\title{
Dean and surgeon
}

\author{
Robin Williamson
}

J R Soc Med 2005;98:218-219

'Humility may clothe an English dean'—William Cowper (1731-1800), Truth

The word dean derives from the Latin decanus - a person set over ten. Since the RSM boasts an Associate Dean, an Emeritus Dean and eight Regional Sub-Deans, the arithmetic tallies. I somehow doubt, dear reader in 2055, whether this will be so in fifty years' time. What do the Deans of the RSM actually do, and how did the Society manage without such creatures for nigh on 190 of its 200 years?

When appointed to the post four years ago, my list of duties began with 'directing the academic policy and strategy of the RSM Academic Department and ensuring high quality educational activities'. These activities are basically of two types - those of the 54 Sections and those of the Society as a whole — and each component has its own team of administrators within 'my' department. Since the RSM is historically the sum of its semiautonomous Sections, it would be a rash Dean who strove to interfere greatly with their activity when they run smoothly, although we do check every programme with a view to accreditation for continuing professional development. By contrast, the Deans play a direct role in Society conferences, and it is the rapid growth of this activity over the last twelve years that especially justifies their existence.

On the milled edge of our current two-pound coin we read that we are 'standing on the shoulders of giants'. My own lofty position is due to my predecessor Deans, Professor Paul Turner (1992-1994), Mr Adrian Marston (1995-1999) and Dr Jack Tinker (1999-2002); their portraits grace the passage to the Academic Department on the third floor at No. 1 Wimpole Street. As Associate Dean, Dr John Scadding is poised to spring onto my own shoulders - alas not gigantic - next year. From this succession it can be seen that various species of doctor have held the deanly post. Experience in hospital

As well as being Dean of the RSM, Robin Williamson, MD FRCS, is consultant surgeon at the Hammersmith Hospital, and Professor of Surgery at Imperial College School of Medicine, London, UK.

Academic Department, Royal Society of Medicine, 1 Wimpole Street, London W1G OAER, UK medicine has been a consistent credential, while some knowledge of postgraduate education has proved equally useful.

Much of our week is occupied with organizing the academic events of the Society as a whole. Many RSM conferences have a strong multidisciplinary nature, as befits an organization that embraces doctors of all description as well as dentists, veterinary practitioners and 'lay' people with an interest in healthcare. Some conferences stick to a narrower clinical theme ('Key Advances'), others have a pronounced scientific content ('Bench to Bedside') while others are informal conversaziones. We also arrange various courses - for example, information technology for doctors, medicine for lawyers or coroners. An important part of the job is to represent the Society in dealings with other academic bodies both within medicine (e.g. the Royal Colleges) and beyond (e.g. the Royal Society of Arts), but also overseas (e.g. the New York Academy of Medicine). The breadth of activity is exciting: within the past week, as I write, we have taken part in a conference on ageing held jointly with the King George VI and Queen Elizabeth Foundation, have helped convene a course for the MRCGP examination and have planned the forthcoming Bicentenary Service of the RSM to take place at St George's, Hanover Square. It is also highly educational: over the past four years my own narrow focus on the pancreas has broadened remarkably to include topics as disparate as asthma and bioterrorism, acute neurology and the physiology of sport.

My own week combines the duties of practising surgeon with those of RSM Dean in roughly equal measure. Many doctors cope well with this type of dual role, balancing their clinical duties with those of research scientist or hospital/ practice administrator or society officer. Is it any more difficult for a surgeon? The answer is no, except with regard to the disruptive effect of postoperative complications, which occur unpredictably and at inconvenient times. It is not just that a sudden haemorrhage can interrupt a committee meeting (which might sometimes be welcome); it is that they monopolize one's thought processes until the problem is sorted and sometimes even afterwards. Generally it is only the operating surgeon who knows what is likely to have gone wrong - which is one reason why I prefer operation notes that have been written by the hand that wielded the scalpel. One unresolved problem with 
doctors working in shifts is the inadequate nature of the hand-over process. Can a consultant surgeon ever be off duty? Ought you to remain available, if only remotely, to advise a colleague who has been called in to cope with your own clinical shortcomings, or can you turn off the mobile telephone?

My father was a surgeon, and also a Fellow of the RSM. I never outgrew the childish wish to be the same although my mother, who was a nurse and working in theatres at the time, was able to dilute any aura of glamour (she also had an aversion to brandy after pouring it down too many dying throats). I only wobbled once in my surgical ambition, when siren voices suggested that a 'thinking' doctor commanded a much less restrictive choice of therapies. In fact the voices were both right and wrong. Most people can acquire the technical skills to operate safely, while modern anaesthesia has largely removed the need for speed and amazing coups de main. But some people have persisting difficulty in learning when to operate and what to do. One benefit of modern imaging is that there are fewer surprises at laparotomy. I find it challenging to tackle an open-ended operation, which requires additional or alternative strategies to those planned in advance. Lately I have spent rather more time assisting colleagues in theatre than before, when I was establishing my own career. I find that I have more capacity for lateral thinking in the role of assistant, which is one reason why you should listen to your registrar-listen, but not always acquiesce.
Educational developments such as 'Modernizing Medical Careers' are likely to introduce rather more rigid training ladders in the near future, with surgical trainees selected within two years of qualifying to embark upon a path that leads to independent practice in the discipline. As a consequence, there is renewed focus on assessing aptitude skills in young doctors. I should personally be sorry if too much emphasis were placed on the ability of a potential surgeon to tie knots quickly or to steer an endoscope with dexterity at the expense of other important attributes, both intellectual and personal. Stamina is a useful property in a surgeon - both the physical stamina to cope with a busy life and the mental stamina to climb back on the bicycle after falling. Soon after becoming a consultant surgeon I served on an advisory appointments committee for a similar post at another hospital in my region. The committee included the senior local physician, who asked each candidate whether a surgeon should be 'brave'. Since it was his only question, it assumed some importance. The clever answer, and one that provoked nods of assent, was that the quality of braveness was rather more important in a patient. As the youngest participant I was too scared to ask the physician the right answer, but I now feel brave enough to tell him: I do believe that courage is important when tackling a difficult operation, but not when it veers towards the reckless. Furthermore, if humility should 'clothe a Dean', then it should certainly clothe a surgeon, whose errors can be so glaringly exposed. 